\title{
A Double Mutation in the Conserved Motifs of the Helper Component Protease of Papaya Leaf Distortion Mosaic Virus for the Generation of a Cross-Protective Attenuated Strain
}

\author{
Decai Tuo, ${ }^{1,2}$ Peng Zhou, ${ }^{1,2}$ Guangyuan Zhao, ${ }^{1,3}$ Pu Yan, ${ }^{1,2}$ Dong Tan, ${ }^{1}$ Xiaoying Li, ${ }^{1,2}$ and Wentao Shen ${ }^{1,2, \dagger}$ \\ ${ }^{1}$ Key Laboratory of Biology and Genetic Resources of Tropical Crops, Ministry of Agriculture \& Institute of Tropical Bioscience and \\ Biotechnology, Chinese Academy of Tropical Agricultural Sciences, Haikou 571101, China \\ ${ }^{2}$ Hainan Key Laboratory of Tropical Microbe Resources, Haikou 571101, China \\ ${ }^{3}$ Institute of Tropical Agriculture and Forestry, Hainan University, Haikou 570228, China \\ Accepted for publication 6 September 2019.
}

\begin{abstract}
Potyviral helper component protease (HC-Pro), as a major determinant of symptom expression in susceptible plants, is a likely target candidate in the production of attenuated strains for cross-protection. In this study, single or double mutations of Lys (K) to Glu (E) in the Lys-Ile-Thr-Cys motif and Arg (R) to Ile (I) in the Phe-Arg-Asn-Lys motif of the HC-Pro

attenuated double mutant of PLDMV-EI presented as symptomless. PLDMV-EI provided effective protection against PLDMV-DF infection in three papaya cultivars and had no effect on plant growth and development. Our result showed that PLDMV-EI is a promising mild strain for the practical use of cross-protection in the field.
\end{abstract} from the severe papaya leaf distortion mosaic virus strain DF (PLDMVDF) reduced symptom expression and virus accumulation in infected papaya (Carica papaya) plants. The papaya plants infected with the
Keywords: attenuated strain, cross-protection, HC-Pro, papaya, PLDMV, virology
Viral cross-protection in plants refers to a natural phenomenon in which a mild or attenuated virus can protect plants against subsequent challenges by other more severe strains of the same or a closely related virus (Zhang and Qu 2016; Ziebell and Carr 2010; Ziebell and MacDiarmid 2017). Cross-protection has been documented for $>35$ plant viruses since it was first observed with tobacco mosaic virus in 1929 (McKinney 1929; Pechinger et al. 2019; Ziebell and Carr 2010). It provides an efficient method to control plant viral diseases, particularly for those having no available control strategies or resistant cultivars (Ziebell and MacDiarmid 2017). The mild strains of citrus tristeza virus (CTV) (Folimonova 2013; Lee and Keremane 2013) and pepino mosaic virus (http://pmv-01.com/) have been widely used to successfully cross-protect against their more damaging viral variants in some countries. The mechanism of viral crossprotection is not clearly elucidated, although several different hypotheses have been proposed. Earlier studies tended to support homology-based RNA silencing as a common mechanism for cross-protection, because cross-protection only seems to work between very closely related isolates of the same virus (Ding and Voinnet 2007; Ratcliff et al. 1997). However, some experimental evidence showed that the cross-protection with turnip crinkle virus or cucumber mosaic virus can still be established in RNA silencing-deficient plants (Ziebell and Carr 2009; Ziebell et al. 2007). The exclusion of CTV strains was unrelated to the production of viral small RNAs (Folimonova et al. 2014). Thus, superinfection exclusion (SIE) is another explanation of cross-protection in which closely related viral

\section{†Corresponding author: W. Shen; dnaswt@hotmail.com}

Funding: This work was supported by Innovative Research Team of the Natural Science Foundation of Hainan Province, China grant 2018CXTD343 and Central Public Interest Scientific Institution Basal Research Fund for Chinese Academy of Tropical Agricultural Sciences grants 19CXTD-33 and 1630052019026.

*The $\boldsymbol{e}$-Xtra logo stands for "electronic extra" and indicates that two supplementary figures and two supplementary tables are published online.

The author(s) declare no conflict of interest.

(C) 2020 The American Phytopathological Society isolates exclude each other at the cellular and/or organismal levels (Dietrich and Maiss 2003; Folimonova 2012). Studies proposed that SIE is related to cell rearrangement induced by initial virus and virus genome fidelity (Zhang et al. 2018; Ziebell and MacDiarmid 2017). However, SIE for CTV is not a simple genotype-specific likefor-like model, but it is determined by host-specific tissue tropism and the relative fitness between the protective and challenge CTV isolates (Harper et al. 2017). Therefore, there are multiple mechanisms of viral cross-protection in plants, and different plant viruses may operate their own distinct strategies for cross-protection.

Papaya (Carica papaya L.) is an economically important tropical fruit with high nutritional and medicinal values. The potyvirus papaya ringspot virus (PRSV) was the causal agent of the most widespread and destructive disease affecting papaya production worldwide before commercial PRSV-resistant transgenic papaya was used to successfully control PRSV in Hawaii (U.S.A.) and southern China (Gonsalves 1998; Ye and Li 2010). However, another potyvirus, papaya leaf distortion mosaic virus (PLDMV), which causes disease symptoms similar to those of PRSV, was identified in a commercial PRSV-resistant transgenic papaya field in China (Bau et al. 2008; Tuo et al. 2013). Furthermore, mixed infections of PRSV and PLDMV were also reported in papaya (Shen et al. 2014). Thus, PLDMV is becoming a new major limiting factor for the economical production of papaya in China. Several common measures, including quarantine, rogueing, and chemical control, have been used to control PLDMV, but they are not effective solutions, because aphids can quickly transmit the virus. Up to now, no PLDMV-resistant papaya varieties are available by conventional breeding methods. The safety and human health-related effects of genetically modified organisms as food continue to be debated, although transgenic papaya lines resistant to both PRSV and PLDMV were documented (Kung et al. 2009). In this situation, cross-protection may be a good alternative to control PLDMV.

Helper component protease (HC-Pro) is a well-known potyviral multifunctional protein involved in polyprotein processing, aphid transmission, and the suppression of antiviral RNA silencing (Maia et al. 1996; Valli et al. 2018). HC-Pro includes multiple domains, 
such as a zinc finger motif and Lys-Ile-Thr-Cys (KITC) domain in the N-terminal region; DRK, Phe-Arg-Asn-Lys (FRNK), IGN, and CCC domains in the central region; and cysteine protease and PTK domains in the C-terminal domain (Maia et al. 1996; Valli et al. 2018). Single- or multiple-amino acid mutations in these HC-Pro domains from tobacco vein mottling virus (Atreya et al. 1992), zucchini yellow mosaic virus (ZYMV) (Desbiez et al. 2010; Gal-On 2000; Kung et al. 2014; Lin et al. 2007), PRSV (Chiang et al. 2007; Huang et al. 2019), and clover yellow vein virus (Yambao et al. 2008) decreased symptom expression. Therefore, HC-Pro is a major determinant of symptom expression in different plants infected with potyviruses. HC-Pro mutations are good target candidates in the production of useful attenuated strains for cross-protection. In this work, we engineered a mild strain of PLDMV for cross-protection by mutating two conserved amino acids, Lys (K) to Glu (E) in the KITC motif and Arg (R) to Ile (I) in the FRNK motif, of the HC-Pro gene of a severe strain, PLDMV-DF (Tuo et al. 2013). The double mutant dramatically reduced symptom expression in papaya plants and conferred complete protection against PLDMV-DF in three papaya cultivars.

\section{MATERIALS AND METHODS}

Plant materials and infectious viral complementary DNA clone. Carica papaya L seedlings of three papaya cultivars (cultivar Suizhonghong, cultivar Mihong, and the commercial PRSV-resistant transgenic cultivar Huanong No. 1) were grown in a greenhouse maintained under 16 -h light $\left(28^{\circ} \mathrm{C}\right)$ and 8 -h dark $\left(25^{\circ} \mathrm{C}\right)$ conditions. The severe PLDMV-DF strain (GenBank accession no. JX974555) used in this study was originally isolated from the PRSVresistant transgenic Huanong No. 1 in Hainan province, China (Tuo et al. 2013). The agroinfection-compatible full-length infectious complementary DNA (cDNA) clone of PLDMV-DF and two fluorescent protein-tagged PLDMV-DF strains (PLDMV-GFP and PLDMV-mCherry) (Tuo et al. 2017, 2018) were constructed previously.

Point mutations in the HC-Pro of PLDMV-DF. The infectious clones containing single or double mutations of the PLDMV HC-Pro open reading frame were constructed using onestep Gibson assembly and direct Agrobacterium tumefaciens transformation using a previously published procedure (Tuo et al. 2017). In brief, the previously constructed pPLDMV-DF plasmid that contained the full-length cDNA of the PLDMV-DF genome was used as the template to amplify various PLDMV fragments (Tuo et al. 2013). Single-site mutated fragments I and III, from $\mathrm{K}_{53}$ to $\mathrm{E}$ in the KITC motif and $\mathrm{R}_{183}$ to I in the FRNK motif of the HCPro, respectively (Fig. 1), were obtained by PCR with specific primer pairs (Supplementary Table S1). The fragment (V) containing mutations in both motifs was produced using the clone containing the mutated KITC at residue $\mathrm{K}_{53}$ as the template by PCR with specific primer pairs (Supplementary Table S1). Then, each mutated fragment (I, III, or V) was assembled into the PLDMV genome with another PLDMV fragment (II or IV) and the minibinary vector pGreenII-35S PCR fragment (Hellens et al. 2000) by Gibson assembly (Fig. 1) as described in the Gibson Assembly Cloning Master Mix's instructions (NEB). Furthermore, the Gibson assembly reaction products were independently directly transformed into A. tumefaciens strain GV3101 in a pSoup plasmid (Tuo et al. 2017, 2018). All of the mutants were confirmed by sequencing plasmids from the positive $A$. tumefaciens transformants.

Plant agroinfiltration and virus mechanical inoculation. Agroinfiltration was performed as described previously (Tuo et al. 2017). A single colony of A. tumefaciens for each infectious clone was grown overnight at $28^{\circ} \mathrm{C}$. Then, the inoculation cultures were prepared with infiltration buffer $(10 \mathrm{mM} \mathrm{MgCl} 2,10 \mathrm{mM} 2-(\mathrm{N}-$ Morpholino) ethanesulfonic acid [pH 5.5], and $100 \mu \mathrm{M}$ acetosyringone) to reach an optical density at $600 \mathrm{~nm}\left(\mathrm{OD}_{600}\right)$ of 0.5 and incubated for 2 to $3 \mathrm{~h}$ at room temperature in the dark. About 7- to 8week-old papaya seedlings were chosen, and the first fully expanded three leaves counting from the top of each plant were infiltrated using a 1-ml needless syringe. The back side of each leaf was injected with $100 \mu \mathrm{l}$ of agrobacterium mixtures. For mechanical inoculation, fresh tissues infected with virus were ground with 1:6 (wt/vol) tissue:buffer (0.01 M potassium phosphate buffer, $\mathrm{pH} 7.0$ ), and debris was removed. Two fully expanded leaves of each test plants were dusted with carborundum and rubbed with $200 \mu$ l of inoculum on surfaces of the leaves. All inoculated papaya seedlings were grown in a controlled environment with a 16 -h light and 8-h dark photocycle at $25^{\circ} \mathrm{C}$.

Cross-protection assays. Three papaya cultivars (Suizhonghong, Mihong, and the PRSV-resistant transgenic Huanong No. 1) susceptible to PLDMV-DF were used to evaluate the crossprotection capacities of the attenuated mutants. The papaya plants were primarily inoculated with an individual mild virus or mock inoculated with the buffer on the first fully expanded three leaves counting from the top of each plant for systemic spread. At 10 days postinfection (dpi), the plants infected with the individual mild virus were challenged with the severe PLDMV-GFP on upper young leaves by agroinfiltration. Protection was evaluated by the daily observation of leaf symptoms, GFP fluorescence, and reverse transcription PCR (RT-PCR). A total of 20 plants for each protective assay were assessed, and each experiment was repeated three times.

Double-antibody sandwich enzyme-linked immunosorbent assay. The upper uninoculated leaves from plants infected with PLDMV or its mutants were homogenized in $0.01 \mathrm{M}$ phosphatebuffered saline containing $0.05 \%$ Tween 20 . The accumulation levels of PLDMV and its mutants in systemically infected plants were determined using double-antibody sandwich enzyme-linked immunosorbent assay (DAS-ELISA) with the antiserum to the PLDMV coat protein (CP). The DAS-ELISA results were read at $405 \mathrm{~nm}$ using a microplate reader (Synergy H1; Bio-Tek).

RT-PCR and quantitative RT-PCR. RNA extraction and reverse transcription were performed as described previously (Tuo et al. 2013, 2018). For RT-PCR, the mutated HC-Pro region was amplified using primers pldmv1607F/pldmv2293R (Supplementary Table S1), and then, all of the mutated sites were confirmed by sequencing the predicted amplified fragments. A primer pair pldmv9000F/pldmv9508R, which flanked the GFP or mCherry cistron at the $3^{\prime}$ end of the $\mathrm{NIb}$ and the $5^{\prime}$ end of the CP gene (Supplementary Table S1) (Tuo et al. 2018), was used to determine the PLDMV-GFP and PLDMV mutants in upper noninoculated papaya leaves at 25 days postchallenge inoculation (dpci) in cross-protection assays. For quantifying PLDMV or its mutant RNA accumulation levels after various time points of inoculation, quantitative RT-PCR was performed with specific primers of PLDMV CP (Huo et al. 2015) as described previously. Papaya actin was used as an internal control

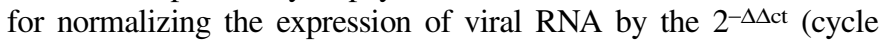
threshold) method (Livak and Schmittgen 2001; Shen et al. 2010). Each experiment included three biological replicates.

SIE assay. Papaya seedlings were first agroinfiltrated with PLDMV-GFP or PLDMV-mCherry $\left(\mathrm{OD}_{600}=0.5\right)$. The symptomatic leaf of papaya at 10 dpi was challenge inoculated with the corresponding PLDMV-mCherry or PLDMV-GFP. For coinfiltration, equal volumes $\left(\mathrm{OD}_{600}=1\right)$ of each $A$. tumefaciens culture containing PLDMV-GFP and PLDMV-mCherry constructs were mixed for infiltration. The upper noninoculated leaves of papaya plants at $20 \mathrm{dpci}$ or 30 days postcoinfiltration were used to examine the SIE under a fluorescence microscope.

Fluorescence examination. The GFP and mCherry fluorescence were observed under a fluorescence microscope (Axio Scope A1; Carl Zeiss) with excitation wavelengths 475 and $590 \mathrm{~nm}$ or a ultraviolet lamp (BLAK RAY B-100AP; UVP).

\section{RESULTS}

Mutations of the conserved residues of PLDMV-DF HCPro for symptom attenuation. The HC-Pro amino acid sequences from five PLDMV isolates and other known severe 
potyviruses were aligned using Vector NTI Advance 11.5 software (Invitrogen). There were highly conserved KITC and FRNK motifs among the PLDMV isolates and most of the potyviruses (Supplementary Fig. S1). To obtain an attenuated PLDMV strain for crossprotection, the amino acid residues $\mathrm{K}$ in the KITC motif and $\mathrm{R}$ in the FRNK motif were selected for mutation. Two single mutants and a double mutant were constructed as follows: $\mathrm{K}$ to $\mathrm{E}$ at residue $53\left(\mathrm{~K}_{53} \mathrm{E}\right), \mathrm{R}$ to $\mathrm{I}$ at residue $183\left(\mathrm{R}_{183} \mathrm{I}\right)$, and $\mathrm{K}$ to $\mathrm{E}$ and $\mathrm{R}$ to $\mathrm{I}$ at residues 53 and $183\left(\mathrm{~K}_{53} \mathrm{R}_{183} \mathrm{EI}\right)$ of PLDMV HC-Pro, respectively. Subsequently, three corresponding infectious clones containing single or double mutations were constructed using A. tumefaciens for both cloning and inoculation (Tuo et al. 2017). All of the mutated sites were confirmed by sequencing. The infectious clonal mutants containing $\mathrm{K}_{53} \mathrm{E}, \mathrm{R}_{183} \mathrm{I}$, and $\mathrm{K}_{53} \mathrm{R}_{183} \mathrm{EI}$ substitutions were designated as PLDMV-E, PLDMV-I, and PLDMV-EI, respectively (Fig. 1).

PLDMV HC-Pro mutants result in attenuated symptoms. To investigate the infectivity and disease symptoms caused by the three PLDMV infectious clonal mutants (PLDMV-E, PLDMV-I, and PLDMV-EI) or the severe PLDMV-DF, papaya plants (Suizhonghong) were independently agroinoculated. The plants infected with PLDMV-DF started to show obvious mosaic symptoms at 15 dpi. At $25 \mathrm{dpi}$, the wild-type PLDMV-DF caused severe mosaic, mottling, and distortion of the leaves and water-soaked streaks on stems, whereas the PLDMV-E and PLDMV-I mutants induced milder mosaic symptoms without leaf distortion than the wild-type

\section{PLDMV-DF(WT)}
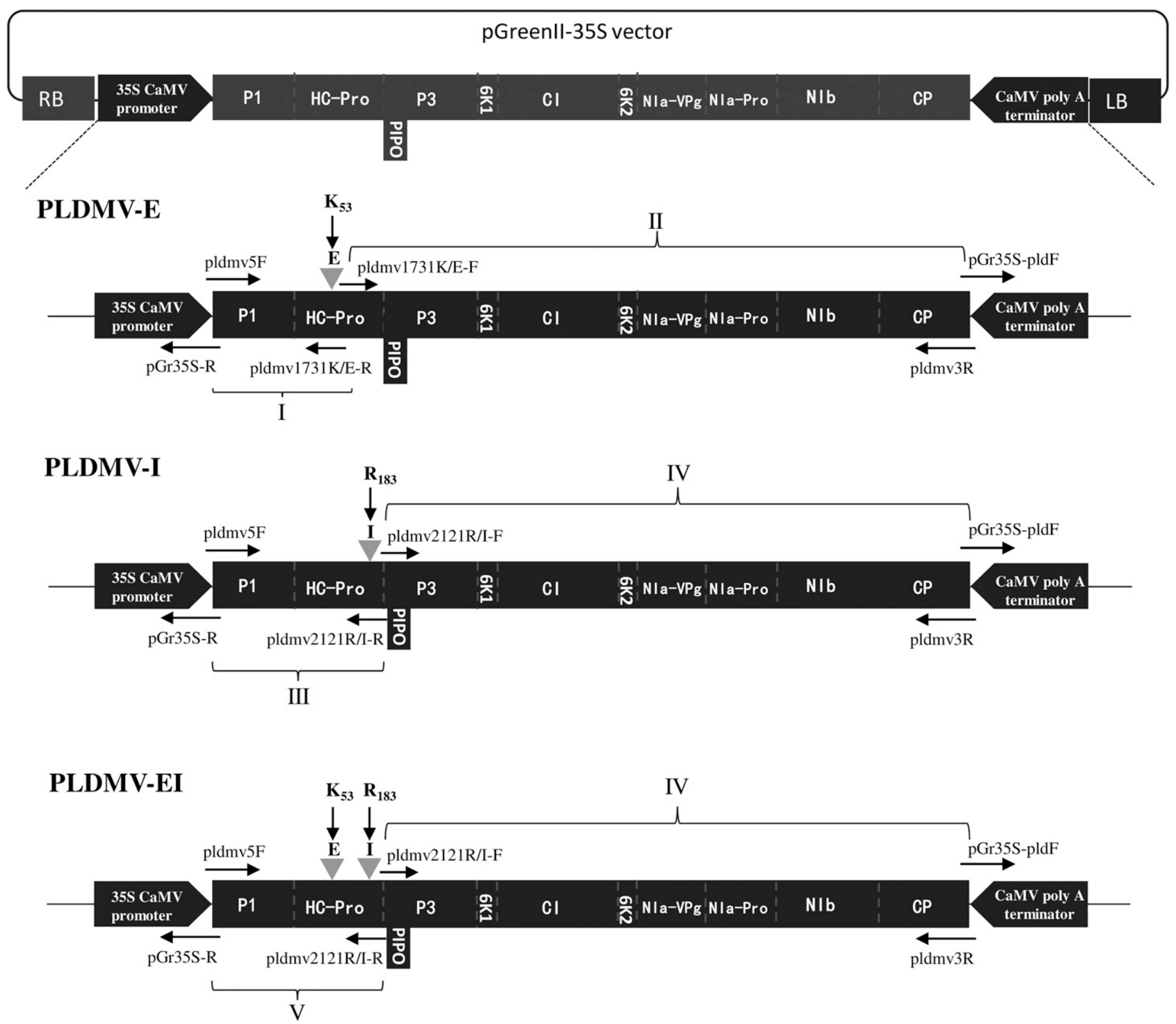

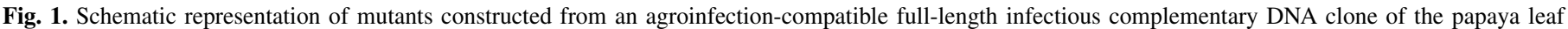

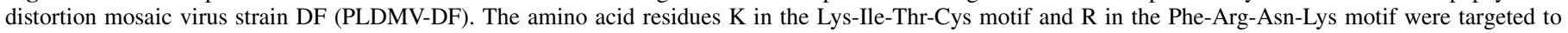

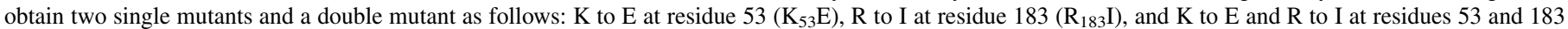

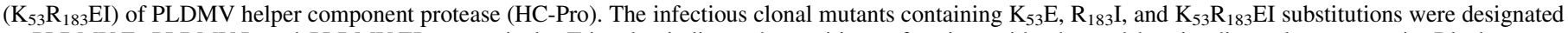

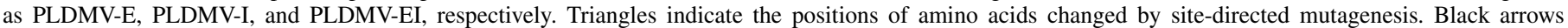

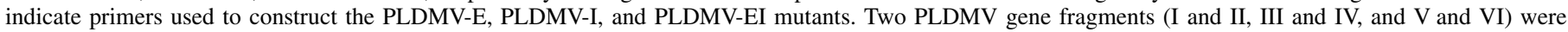

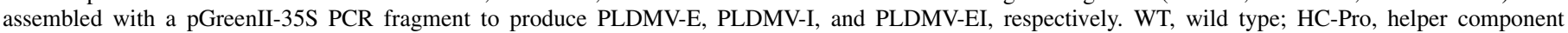

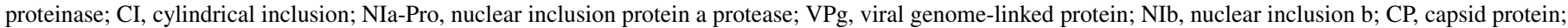
PIPO, pretty interesting potyviral protein; CaMV, cauliflower mosaic virus; and LB and RB, left and right borders of the T-DNA. 
PLDMV-DF. At the same time, the double-mutant PLDMV-EIinfected papaya plants presented symptomless leaves but less obvious water-soaked streaks on stems than the wild-type PLDMV-DF, PLDMV-E, and PLDMV-I mutants. The mild symptoms induced by PLDMV-E and PLDMV-I continued to be observed at $60 \mathrm{dpi}$, but the mild water-soaked streaks on stems infected with PLDMV-EI disappeared, and there was little difference in the growth rates between the PLDMV-EI-infected plants and mock controls (Fig. 2A). The DAS-ELISA and quantitative RT-PCR results showed that both single and double mutants reduced substantially the accumulation of PLDMV CP and RNA in leaves of infected plants at 25 and 60 dpi, respectively (Fig. 2B and C). The accumulation of the PLDMV-EI in systemically infected leaves was similar to the level of PLDMV-I but lower than that of PLDMV-E (Fig. 2B and C). Thus, the point mutations in the KITC and FRNK motifs of PLDMV HC-Pro seemed to alter symptom expression in papaya plants and reduced the accumulation of PLDMV. In addition, the double-mutant PLDMV-EI was capable of systemically infecting papaya plants, whereas the leaves remained
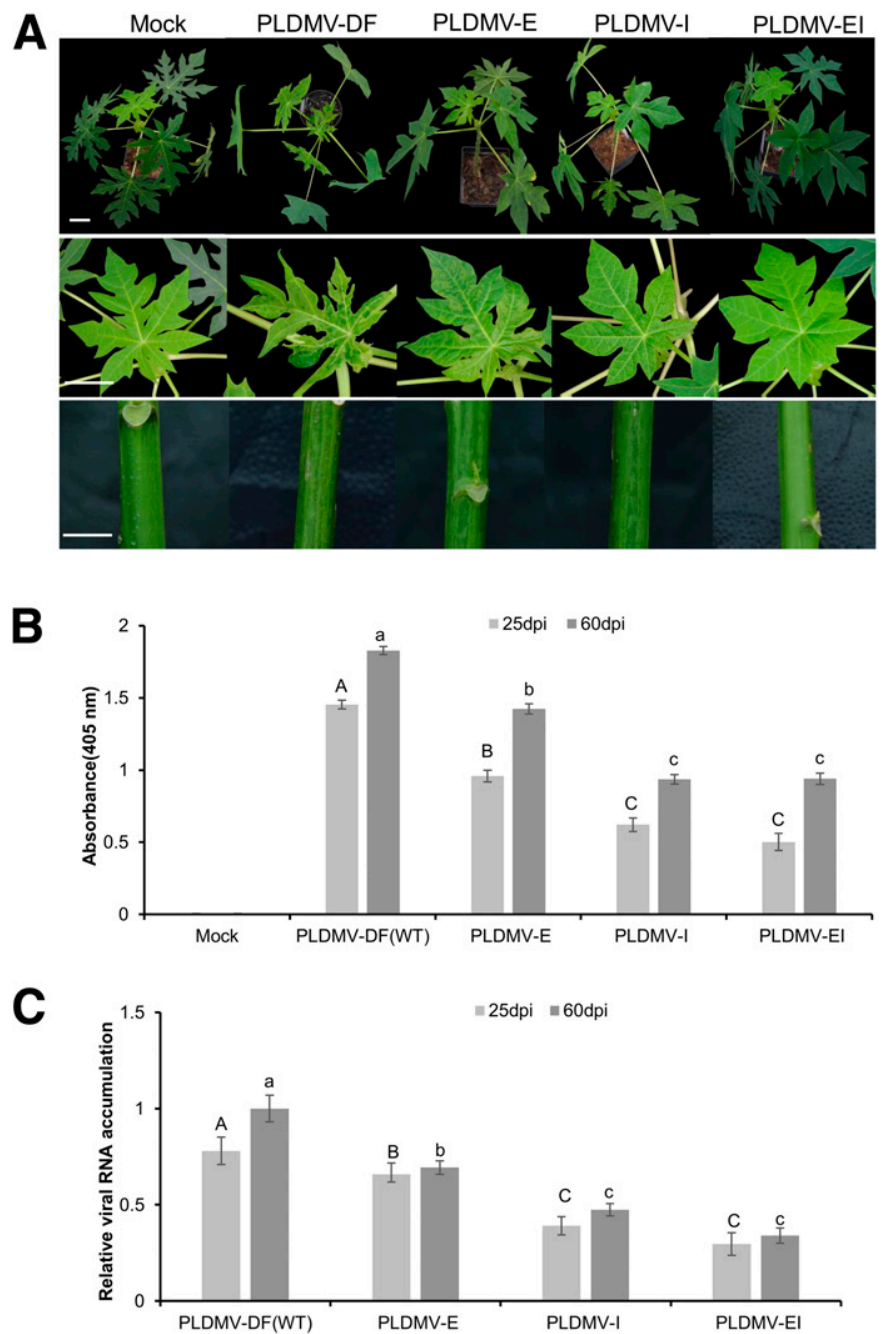

Fig. 2. Infectivity levels of three papaya leaf distortion mosaic virus (PLDMV) mutants. A, Systemic symptoms induced by the wild-type (WT) virus or three mutants (PLDMV-E, PLDMV-I, and PLDMV-EI) on papaya plants (cultivar Suizhonghong) at 60 days postinoculation (dpi). The scale bar represents $1 \mathrm{~cm}$. B, Detection of the accumulation of the coat protein of the WT or three PLDMV mutants in infected papaya leaves as assessed by indirect enzymelinked immunosorbent assays at 25 and 60 dpi. C, Relative accumulation of PLDMV-E, PLDMV-I, and PLDMV-EI RNA in systemic leaves at 25 and 60 dpi determined by reverse transcription quantitative PCR. Bars represent mean \pm standard deviation $(n=3)$. Different letters (uppercase and lowercase letters refer to 25 and $60 \mathrm{dpi}$, respectively) indicate significant mean differences at $P<0.05$ ranked by one-way analysis of variance and Duncan's multiple range test. symptomless. Thus, the double mutation is a candidate for eliciting cross-protection.

Primary attenuated PLDMV-EI infection provides effective protection against severe PLDMV infection. The infectious clone PLDMV-GFP, which was constructed based on a severe isolate of PLDMV-DF, was used to evaluate the crossprotective effects of PLDMV-EI. Each mock-inoculated control for the three papaya cultivars (Suizhonghong, Mihong, and the PRSVresistant transgenic Huanong No 1) showed prominent mosaicism and distortions on the upper leaves at 25 dpci when infected with PLDMV-GFP (Fig. 3A). In contrast, the PLDMV-EI-inoculated papaya cultivars were protected against PLDMV-GFP, showing no visual symptoms at $25 \mathrm{dpci}$ (Fig. 3A), and the effects of crossprotection were observed until $180 \mathrm{dpci}$. In addition, no GFP fluorescence was detected in any of the papaya plants primarily infected with PLDMV-EI at 25 dpci, but all of the mock-inoculated controls displayed GFP fluorescence when challenged with PLDMV-GFP(Fig. 3A). The RT-PCR results confirmed the absence of the PLDMV-GFP genome in the cross-protected papaya plants according to the amplified fragments of approximately 509- and 1,250-base pairs from PLDMV-DF- and PLDMV-GFP-infected papaya plants, respectively (Fig. 3B). In addition, the DAS-ELISA showed that there were similar levels of virus accumulation between the plants infected with only PLDMV-EI and those cross-protected by PLDMV-EI (Fig. 3C). The results indicated that the primary attenuated PLDMV-EI infection provided effective protection against severe PLDMV infection in the three papaya cultivars.

The PLDMV-EI mutants are genetically stable. The stability of the substituted amino acids in the PLDMV-EI double mutant after infection was monitored during six serial passages by mechanical inoculation in papaya plants at 30-day intervals. The consistent lack of symptoms on all of the inoculated plants remained unchanged compared with the first passage. A sequence analysis of HC-Pro RT-PCR products from papaya plants infected with PLDMV-EI at 30 dpi of the sixth serial passage revealed that the $\mathrm{K}_{53} \mathrm{E}$ and $\mathrm{R}_{183} \mathrm{I}$ mutations were maintained through the passages (Supplementary Fig. S2). Thus, the HC-Pro in the PLDMV-EI double mutant did not revert to the wild type.

\section{DISCUSSION}

The major goal of this study was to obtain effective mild PLDMV strains as a protectant for control of PLDMV. As early as 1984, the nitrous acid-induced mild mutant HA5-1 or HA6-1 was successfully applied to control a severe PRSV strain in Taiwan and Hawaii (Sheen et al. 1998; Yeh and Gonsalves 1984; Yeh et al. 1988), which provided the foundation for developing the cross-protection against PLDMV. The production and selection of protective mild viral strains are essential. In 2017, a novel and rapid A. tumefaciensmediated approach for both cloning and inoculating was developed to generate stable infectious clones of PLDMV (Tuo et al. 2017). This made it possible to more rapidly obtain various attenuated PLDMV strains through site-directed mutagenesis than other methods, such as natural selection and chemical and physical mutagenesis. In this study, two conserved amino acids, $\mathrm{K}$ in the KITC motif and R in the FRNK motif, of the HC-Pro from the severe strain of PLDMV-DF were selected as targets for single and double mutations. The resulting three PLDMV mutants reduced symptom expression and virus accumulation in infected papaya plants. Interestingly, the papaya plants infected with the attenuated double mutant of PLDMV-EI presented as symptomless at 60 dpi. PLDMV-EI provided effective protection against PLDMV-DF infection in three papaya cultivars and had no effect on plant growth and development. Thus, PLDMV-EI is a useful and promising mild strain for cross-protection against PLDMV severe strains.

Among the different potyviruses, the mutation of $\mathrm{R}$ to $\mathrm{I}$ in the FRNK motif resulted in different levels of virus accumulation and 
symptom expression. For example, the substitution of $\mathrm{R}$ to $\mathrm{I}$ in the FRNK motif of the tobacco etch virus and the turnip mosaic virus leads to the loss of their infectivity (Shiboleth et al. 2007). The replacement of R with I in the FRNK motif of the ZYMV-NAT strain caused a symptomless infection in cucurbits without affecting virus accumulation. However, the same mutation in another ZYMV

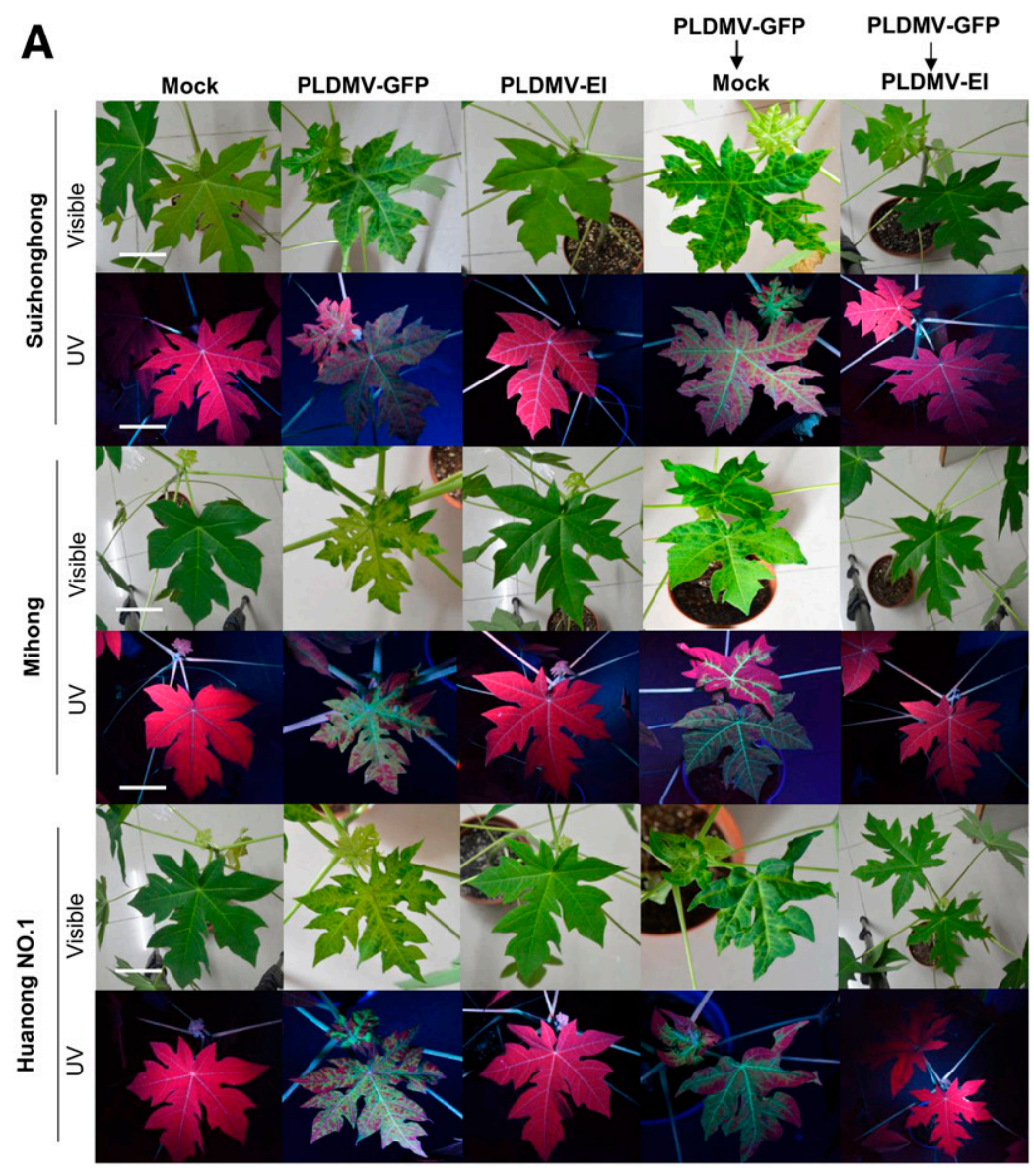

B

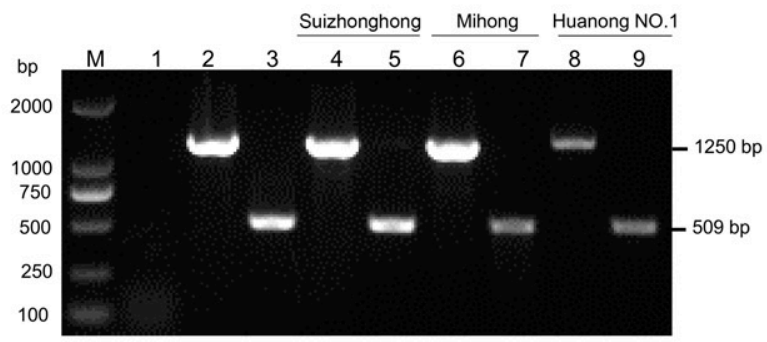

C

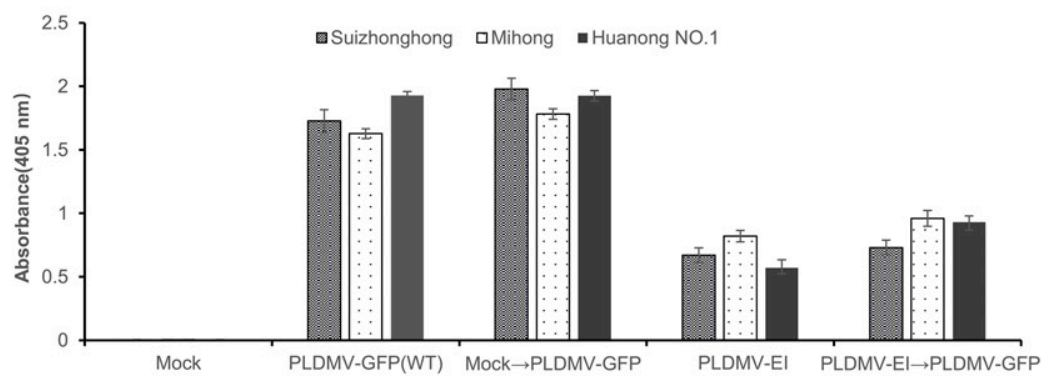

Fig. 3. The PLDMV-EI double-mutant cross-protects three papaya cultivars against wild-type (WT) papaya leaf distortion mosaic virus tagged with GFP (PLDMVGFP). Each papaya cultivar (cultivar Suizhonghong, cultivar Mihong, and the papaya ringspot virus-resistant transgenic cultivar Huanong No. 1) was first infected with buffer only (mock) or mutant PLDMV-EI and then, superinoculated with PLDMV-GFP after 10 days. A, Symptoms and GFP fluorescence levels under visible and ultraviolet (UV) light in superinfected plants at 25 days postchallenge inoculation (dpci). The scale bar represents $4 \mathrm{~cm}$. B, Reverse transcription PCR detection of the mutant PLDMV-EI and PLDMV-GFP in upper noninoculated papaya leaves at 25 dpci in cross-protection assays using the pldmv9000F/R primers flanking the GFP cistron at the $3^{\prime}$ end of the NIb and the $5^{\prime}$ end of the coat protein (CP). The amplified fragments of approximately 509 and 1,250 base pairs from PLDMVDF- and PLDMV-GFP-infected papaya plants, respectively, are indicated. Lane M, 2,000-base pairs DNA ladder. C, Double-antibody sandwich enzyme-linked immunosorbent assay detection of PLDMV CP in leaves of superinfected papaya plants at 25 dpci. 
strain TW-TN3 produced a milder symptom with reduced virus accumulation (Lin et al. 2007; Shiboleth et al. 2007), which is consistent with the result of PLDMV-I and PLDMV-EI mutants. These differences may be related to different HC-Pro structures and other domains of potyviruses involved in pathogenicity (Lin et al. 2007). In ZYMV, it has been hypothesized that the binding of the FRNK motif of HC-Pro with microRNA might affect microRNAmediated gene regulation and result in symptom development (Shiboleth et al. 2007). For the KITC motif, previous studies showed that the mutation of $\mathrm{K}$ to $\mathrm{E}$ in the KITC motif of the potyvirus HC-Pro not only reduced symptoms but also, resulted in loss of HC-Pro function in aphid transmission (Atreya et al. 1992; Blanc et al. 1998). Thus, this mutation might reduce a potential risk of genetically engineered PLDMV-EI being transmitted into the environment by aphid.

It is important to ensure the reliability of the result of crossprotection assays using an inoculation method with high success rate. In this study, the PLDMV-DF, PLDMV-GFP, and its three PLDMV mutants showed $100 \%$ systemic infection rate on agroinfiltrated papaya plants, whereas the success rates were 64 to $76 \%$ by mechanical inoculation when the inoculums were taken from papaya leaves infected with the corresponding PLDMV and its mutants (Supplementary Table S2). Therefore, the inoculation of protective mutant and subsequent challenge by severe PLDMVGFP were performed by agroinfiltration in this study. Particularly,

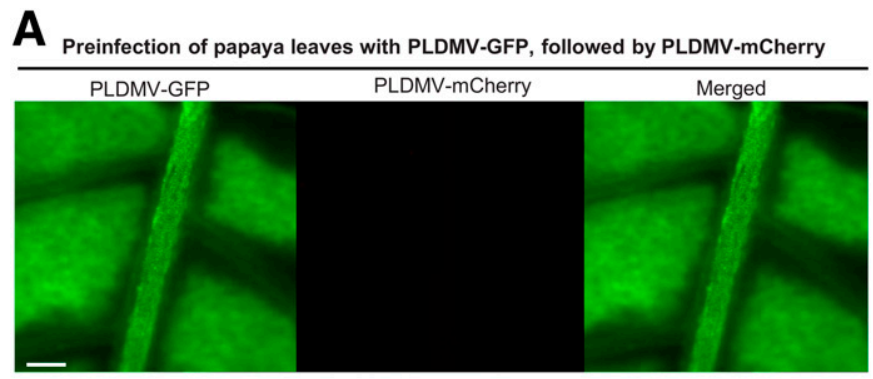

B Preinfection of papaya leaves with PLDMV-mCherry, followed by PLDMV-GFP

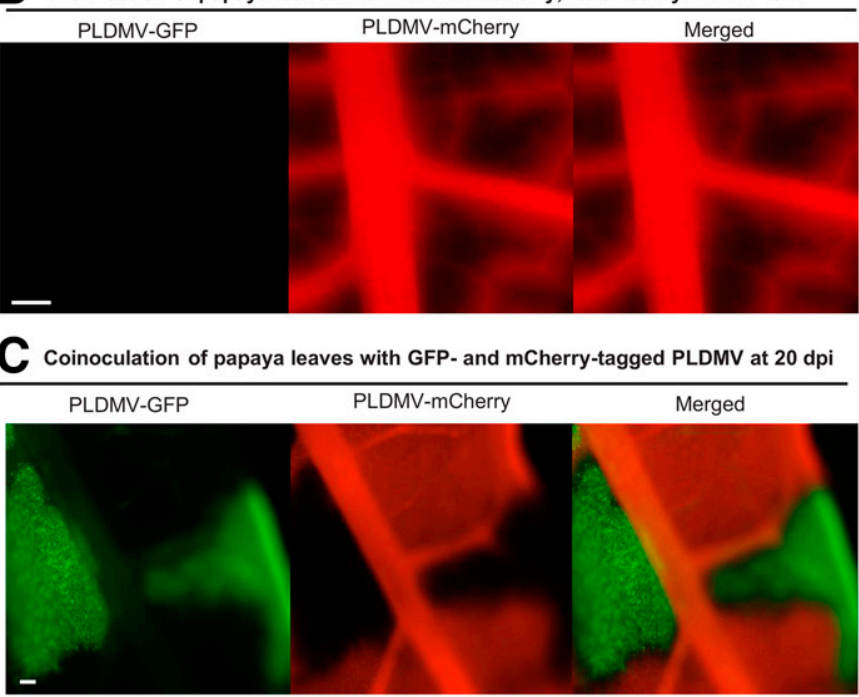

Fig. 4. Distributions of the GFP- and mCherry-tagged papaya leaf distortion mosaic virus (PLDMV-GFP and PLDMV-mCherry, respectively) in coinfected and superinfected papaya plants. A, GFP and mCherry fluorescence levels in upper noninoculated papaya leaves that were first inoculated with PLDMVGFP followed by PLDMV-mCherry after 10 days. B, GFP and mCherry fluorescence levels in upper noninoculated papaya leaves that were first inoculated with PLDMV-mCherry followed with PLDMV-GFP after 10 days. C, GFP and mCherry fluorescence levels in upper noninoculated papaya leaves that were coinoculated with PLDMV-GFP and PLDMV-mCherry at 30 days postinoculation (dpi). Images of superinfection were taken at 20 days after the second virus inoculation. The scale bar represents $20 \mu \mathrm{m}$. the challenger virus PLDMV-GFP was undetectable in plants preinoculated with PLDMV-EI as assessed by GFP fluorescence and RT-PCR. A 2015 study revealed that plants can be transiently transfected by spraying with agrobacterium suspensions using a hand sprayer (Hahn et al. 2015). This simple and fast method might be applied to massively agroinoculate PLDMV-EI on papaya seedings for the practical use of cross-protection.

As mentioned above, the challenger virus PLDMV-GFP was undetectable in plants preinoculated with PLDMV-EI in our crossprotection assays, which suggested that the preexisting PLDMV-EI could block cells that it already occupied from being superinfected by PLDMV-GFP. The SIE may account for at least some aspects of cross-protection against severe PLDMV infection by the attenuated PLDMV-EI. Consequently, we investigated SIE using GFP- and mCherry-tagged PLDMV. The differently labeled PLDMV populations were distributed separately in upper noninoculated leaves at 20 dpi when papaya plants were coinoculated with PLDMV-GFP and PLDMV-mCherry (Fig. 4). In contrast, the systemic infection of papaya leaves by GFP- or mCherry-tagged PLDMV completely prevented superinfection by mCherry- or GFP-tagged PLDMV (Fig. 4). Similar SIE phenomena have been identified by the coinfection of plants with the same two viruses labeled with different fluorescent proteins (Dietrich and Maiss 2003; Miyashita and Kishino 2010; Takahashi et al. 2007; Tatineni and French 2016).

In this study, all results are based on the laboratory or greenhouse test. Therefore, the long-term influence of PLDMV-EI on agronomic traits of papaya and the effectiveness of PLDMV-EI cross-protection against severe strains remain to be confirmed in the field. In addition, it is necessary to have environmental risk assessment of PLDMV-EI before the practical application in view of PLDMV-EI from artificial mutation. So far, no case is reported on the occurrence of recombination of attenuated strains with wild-type virus and reversion to the virulent strain on nontarget hosts (Pechinger et al. 2019). However, it is worth mentioning that mild strain cross-protection might be broken down owing to the climate, the introduction of more severe challenge strains, or new viral transmission vectors (Powell et al. 2003; Rezende and Sherwood 1991; Yeh and Gonsalves. 1984). Therefore, there are still many challenges from the laboratory to the field application for the mild PLDMV-EI mutant.

In summary, this is the first report of a useful attenuated PLDMV, which has mutations in two conserved motifs of HC-Pro, for crossprotection against severe strain infection. It provides a foundation for the control of PLDMV through cross-protection in the field.

\section{LITERATURE CITED}

Atreya, C. D., Atreya, P. L., Thornbury, D. W., and Pirone, T. P. 1992. Sitedirected mutations in the potyvirus HC-Pro gene affect helper component activity, virus accumulation, and symptom expression in infected tobacco plants. Virology 191:106-111.

Bau, H. J., Kung, Y. J., Raja, J. A., Chan, S. J., Chen, K. C., Chen, Y. K., Wu, H. W., and Yeh, S. D. 2008. Potential threat of a new pathotype of Papaya leaf distortion mosaic virus infecting transgenic papaya resistant to Papaya ringspot virus. Phytopathology 98:848-856.

Blanc, S., Ammar, E. D., Garcia-Lampasona, S., Dolja, V. V., Llave, C., Baker, J., and Pirone, T. P. 1998. Mutations in the potyvirus helper component protein: Effects on interactions with virions and aphid stylets. J. Gen. Virol. 79:3119-3122.

Chiang, C. H., Lee, C. Y., Wang, C. H., Jan, F. J., Lin, S. S., Chen, T. C., Raja, J. A. J., and Yeh, S. D. 2007. Genetic analysis of an attenuated Papaya ringspot virus strain applied for cross-protection. Eur. J. Plant Pathol. 118:333-348.

Desbiez, C., Girard, M., and Lecoq, H. 2010. A novel natural mutation in HCPro responsible for mild symptomatology of zucchini yellow mosaic virus (ZYMV, Potyvirus) in cucurbits. Arch. Virol. 155:397-401.

Dietrich, C., and Maiss, E. 2003. Fluorescent labelling reveals spatial separation of potyvirus populations in mixed infected Nicotiana benthamiana plants. J. Gen. Virol. 84:2871-2876.

Ding, S. W., and Voinnet, O. 2007. Antiviral immunity directed by small RNAs. Cell 130:413-426.

Folimonova, S. Y. 2012. Superinfection exclusion is an active virus-controlled function that requires a specific viral protein. J. Virol. 86:5554-5561. 
Folimonova, S. Y. 2013. Developing an understanding of cross-protection by Citrus tristeza virus. Front. Microbiol. 4:76.

Folimonova, S. Y., Harper, S. J., Leonard, M. T., Triplett, E. W., and Shilts, T. 2014. Superinfection exclusion by Citrus tristeza virus does not correlate with the production of viral small RNAs. Virology 468-470:462-471.

Gal-On, A. 2000. A point mutation in the FRNK motif of the potyvirus helper component-protease gene alters symptom expression in cucurbits and elicits protection against the severe homologous virus. Phytopathology 90: 467-473.

Gonsalves, D. 1998. Control of papaya ringspot virus in papaya: A case study. Annu. Rev. Phytopathol. 36:415-437.

Hahn, S., Giritch, A., Bartels, D., Bortesi, L., and Gleba, Y. 2015. A novel and fully scalable Agrobacterium spray-based process for manufacturing cellulases and other cost-sensitive proteins in plants. Plant Biotechnol. J. 13: 708-716.

Harper, S. J., Cowell, S. J., and Dawson, W. O. 2017. Isolate fitness and tissuetropism determine superinfection success. Virology 511:222-228.

Hellens, R., Mullineaux, P., and Klee, H. 2000. Technical focus: A guide to Agrobacterium binary Ti vectors. Trends Plant Sci. 5:446-451.

Huang, X. D., Fang, L., Gu, Q. S., Tian, Y. P., Geng, C., and Li, X. D. 2019. Cross protection against the watermelon strain of Papaya ringspot virus through modification of viral RNA silencing suppressor. Virus Res. 265: 166-171.

Huo, P., Shen, W. T., Yan, P., Tuo, D. C., Li, X. Y., and Zhou, P. 2015. Simultaneous detection of papaya ringspot virus, papaya leaf distortion mosaic virus, and papaya mosaic virus by multiplex real-time reverse transcription PCR. Acta Virol. 59:380-388.

Kung, Y. J., Bau, H. J., Wu, Y. L., Huang, C. H., Chen, T. M., and Yeh, S. D. 2009. Generation of transgenic papaya with double resistance to Papaya ringspot virus and Papaya leaf-distortion mosaic virus. Phytopathology 99: 1312-1320.

Kung, Y. J., Lin, P. C., Yeh, S. D., Hong, S. F., Chua, N. H., Liu, L. Y., Lin, C. P., Huang, Y. H., Wu, H. W., Chen, C. C., and Lin, S. S. 2014. Genetic analyses of the FRNK motif function of Turnip mosaic virus uncover multiple and potentially interactive pathways of cross-protection. Mol. Plant-Microbe Interact. 27:944-955

Lee, R. F., and Keremane, M. L. 2013. Mild strain cross protection of tristeza: A review of research to protect against decline on sour orange in Florida. Front. Microbiol. 4:259.

Lin, S. S., Wu, H. W., Jan, F. J., Hou, R. F., and Yeh, S. D. 2007. Modifications of the helper component-protease of zucchini yellow mosaic virus for generation of attenuated mutants for cross protection against severe infection. Phytopathology 97:287-296.

Livak, K. J., and Schmittgen, T. D. 2001. Analysis of relative gene expression data using real-time quantitative PCR and the 2(-Delta Delta $\mathrm{C}(\mathrm{T})$ ). Methods 25:402-408.

Maia, I. G., Haenni, A., and Bernardi, F. 1996. Potyviral HC-Pro: A multifunctional protein. J. Gen. Virol. 77:1335-1341.

McKinney, H. H. 1929. Mosaic diseases in the Canary Islands, West Africa and Gibraltar. J. Agric. Res. 39:557-578.

Miyashita, S., and Kishino, H. 2010. Estimation of the size of genetic bottlenecks in cell-to-cell movement of soil-borne wheat mosaic virus and the possible role of the bottlenecks in speeding up selection of variations in trans-acting genes or elements. J. Virol. 84:1828-1837.

Pechinger, K., Chooi, K. M., MacDiarmid, R. M., Harper, S. J., and Ziebell, H. 2019. A new era for mild strain cross-protection. Viruses 11:670.

Powell, C. A., Pelosi, R. R., Rundell, P. A., and Cohen, M. 2003. Breakdown of cross-protection of grapefruit from decline-inducing isolates of citrus tristeza virus following introduction of the brown citrus aphid. Plant Dis. 87:1116-1118

Ratcliff, F., Harrison, B. D., and Baulcombe, D. C. 1997. A similarity between viral defense and gene silencing in plants. Science 276:1558-1560.

Rezende, J. A. M., and Sherwood, J. L. 1991. Breakdown of cross protection between strains of tobacco mosaic virus due to susceptibility of dark green areas to superinfection. Phytopathology 81:1490-1496.
Sheen, T. F., Wang, H. L., and Wang, D. N. 1998. Control of papaya ringspot virus by cross protection and cultivation techniques. J. Japan Soc. Hortic. Sci. 67:1232-1235.

Shen, W., Yan, P., Gao, L., Pan, X., Wu, J., and Zhou, P. 2010. Helper component-proteinase (HC-Pro) protein of Papaya ringspot virus interacts with papaya calreticulin. Mol. Plant Pathol. 11:335-346.

Shen, W. T., Tuo, D. C., Yang, Y., Yan, P., Li, X. Y., and Zhou, P. 2014. First report of mixed infection of Papaya ringspot virus and Papaya leaf distortion mosaic virus on Carica papaya L. J. Plant Pathol. 96:121.

Shiboleth, Y. M., Haronsky, E., Leibman, D., Arazi, T., Wassenegger, M., Whitham, S. A., Gaba, V., and Gal-On, A. 2007. The conserved FRNK box in HC-Pro, a plant viral suppressor of gene silencing, is required for small RNA binding and mediates symptom development. J. Virol. 81:13135-13148.

Takahashi, T., Sugawara, T., Yamatsuta, T., Isogai, M., Natsuaki, T., and Yoshikawa, N. 2007. Analysis of the spatial distribution of identical and two distinct virus populations differently labeled with cyan and yellow fluorescent proteins in coinfected plants. Phytopathology 97:1200-1206.

Tatineni, S., and French, R. 2016. The coat protein and NIa protease of two potyviridae family members independently confer superinfection exclusion. J. Virol. 90:10886-10905.

Tuo, D. C., Fu, L. L., Shen, W. T., Li, X. Y., Zhou, P., and Yan, P. 2017. Generation of stable infectious clones of plant viruses by using Rhizobium radiobacter for both cloning and inoculation. Virology 510:99-103.

Tuo, D. C., Shen, W. T., Yan, P., Li, C. Q., Gao, L., Li, X. Y., Li, H. P., and Zhou, P. 2013. Complete genome sequence of an isolate of papaya leaf distortion mosaic virus from commercialized PRSV-resistant transgenic papaya in China. Acta Virol. 57:452-455.

Tuo, D. C., Yan, P., Zhao, G. Y., Li, X. Y., Zhou, P., and Shen, W. T. 2018. Two agroinfection-compatible fluorescent protein-tagged infectious cDNA clones of papaya leaf distortion mosaic virus facilitate the tracking of virus infection. Acta Virol. 62:202-207.

Valli, A. A., Gallo, A., Rodamilans, B., López-Moya, J. J., and García, J. A. 2018. The HCPro from the Potyviridae family: An enviable multitasking Helper Component that every virus would like to have. Mol. Plant Pathol. 19:744-763.

Yambao, M. L., Yagihashi, H., Sekiguchi, H., Sekiguchi, T., Sasaki, T., Sato, M., Atsumi, G., Tacahashi, Y., Nakahara, K. S., and Uyeda, I. 2008. Point mutations in helper component protease of clover yellow vein virus are associated with the attenuation of RNA-silencing suppression activity and symptom expression in broad bean. Arch. Virol. 153:105-115.

Ye, Ch., and Li, H. P. 2010. 20 years of transgenic research in China for resistance to Papaya ringspot virus. Transgenic Plant J. 4:58-63.

Yeh, S. D., and Gonsalves, D. 1984. Evaluation of induced mutants of papaya ringspot virus for control by cross protection. Phytopathology 74: 1086-1091.

Yeh, S. D., Gonsalves, D., Wang, H. L., Nanba, R., and Chiu, R. J. 1988. Control of papaya ringspot virus by cross protection. Plant Dis. 72:375-380.

Zhang, X. F., and Qu, F. 2016. Cross protection of plant viruses: Recent developments and mechanistic implications. Pages 241-250 in: Current Research Topics in Plant Virology. A. Wang and X. Zhou, eds. Springer, Cham, Switzerland.

Zhang, X. F., Zhang, S., Guo, Q., Sun, R., Wei, T., and Qu, F. 2018. A new mechanistic model for viral cross protection and superinfection exclusion. Front. Plant Sci. 9:40.

Ziebell, H., and Carr, J. P. 2009. Effects of dicer-like endoribonucleases 2 and 4 on infection of Arabidopsis thaliana by cucumber mosaic virus and a mutant virus lacking the $2 \mathrm{~b}$ counter-defence protein gene. J. Gen. Virol. 90: 2288-2292.

Ziebell, H., and Carr, J. P. 2010. Cross-protection: A century of mystery. Adv. Virus Res. 76:211-264.

Ziebell, H., and MacDiarmid, R. 2017. Prospects for engineering and improvement of cross-protective virus strains. Curr. Opin. Virol. 26:8-14.

Ziebell, H., Payne, T., Berry, J. O., Walsh, J. A., and Carr, J. P. 2007. A cucumber mosaic virus mutant lacking the $2 \mathrm{~b}$ counter-defence protein gene provides protection against wild-type strains. J. Gen. Virol. 88:2862-2871. 